\title{
Effect of KF Modification to Kaolinite Catalytic Activity in Microwave-Assisted Biodiesel Conversion
}

\author{
Is Fatimah ${ }^{1}$, Dwiarso Rubiyanto ${ }^{2}$, Septian Perwira Yudha ${ }^{2}$ \\ ${ }^{1}$ Department of Chemistry, Universitas Islam Indonesia \\ ${ }^{2}$ Department of Chemistry, UII
}

\begin{abstract}
$\mathbf{P}$ REPARATION of reusable catalyst based on KF-modified kaolinite clay for reusable catalyst application on biodiesel conversion has been investigated. Materials preparation were carried out by simple mixing and solid reaction between KF and kaolinite at various KF loading. The effect of KF content loaded the surface structure and surface basicity have been studied. Characterization of the materials was investigated based on scanning electrone microscopy-energy dispersive-x ray spectroscopy (SEM-EDX) SEM, x-ray diffraction (XRD) and gas sorption analysis. Increasing the reusability and the effectivity of catalysts utilization was studied by comparing reflux method and microwave (MW)-assisted reaction of biodiesel production from Jatropha oil. Results showed that increasing solid basicity is the character plays important role in increasing catalytic activity in biodiesel conversion. By comparing the reaction method, it is found that similar biodiesel yield was obtained with shorter time, higher turnover frequency (TOF) and better reusability over MW assisted-method. Refer to yield and TOF of compared reactions, KF content of $25 \%$ for kaolinite modification is the optimum concentration to produce biodiesel.
\end{abstract}

Keywords: Biodiesel; Clay; Kaolinite; Microwave; KF-modified clay.

\section{Introduction}

Biodiesel still becomes potential alternative energy regarding to the depletion of fossil fuel. The huge potency of raw material in Southeast Asia is the main reason for biodiesel as favorable energy sources and develop the technology of biodiesel conversion. As many other reactions for industrial application, intensification to the process was an interesting attempt. Basic principle of biodiesel conversion is transesterification of plant oil with alcohol, mainly methanol under catalytic mechanism. Generally, $\mathrm{NaOH}$ or $\mathrm{KOH}$ is utilized as homogeneous catalyst which is a nonrenewable and becomes consumable chemical in the process. For this purpose, the utilization of heterogeneous catalyst for replacing nonrenewable homogeneous catalyst is an interesting alternative[1,2].

Many kinds of solid catalysts were reported as alternatives. Main idea of the utilization of the heterogenous catalysts is for increasing reaction rate, yield of production and also the easy in product-catalyst separation. In order to meet these requirements, the use of solid catalysts was investigated. Silica-based solid such as clay, zeolite and other silica-alumina materials and their modified forms were reported to be active as catalyst. Clay materials are characterized as porous, modifiable, stable and high surface area materials and they were reported to be active as catalyst or catalyst support in the purpose of transesterification reactions. Within the scheme of increasing efficiency and effectivity of the catalytic process, some modifications to the solid catalysts were also attempted. Many modified clay minerals such as acid activation, base-activation, metal oxide immobilization and thermal converted forms exhibit the increased performance for catalytic purposes[3-5]mmobilization of some metal oxides for example $\mathrm{LiO}, \mathrm{CuO}, \mathrm{CeO}$ or $\mathrm{ZnO}$ were reported to give excellent contribution for solid basicity which is required for transesterification mechanism [6,7]. Other factors obtained from clay structure are the modifiable properties due to layered form and porous structure. Clay minerals 
itself are characterized as silica alumina structure composed of silica tetrahedral layers joined to alumina octahedral layers in certain composition that affects the specific kind and properties. Kaolinite is a kind of clay mineral with the silica: alumina molar ratio of $1: 1$ and it is available as natural form in abundant amount. As many modifications applied for other clay minerals, several chemical treatments may be attempted in order to utilize kaolinite in catalysis in order to produce low cost catalyst[7].

From many papers, it is noted that basemodified solids exhibit excellent activity in transesterification reactions. Modification of $\mathrm{Al}_{2} \mathrm{O}_{3}$ with $\mathrm{NaOH}$ for example, gives the $99 \%$ conversion of Jatropha oil which is a significant increased value compared to unmodified $\mathrm{Al}_{2} \mathrm{O}_{3}$. From another report, $\mathrm{KOH}$ modification was also given significant not only to biodiesel conversion but also reusability properties. By another scheme, intensification of biodiesel production was reported by utilization of some efficient technologies such as microwave (MW) irradiation and by this technique, fast and efficient method was gained[8]. In this work, KF modification onto clay as catalyst over MW irradiation for biodiesel conversion over is attempted[9]. Even the previous investigation demonstrated that KF modification onto kaolinite material is responsible factor in increasing biodiesel conversion over MW irradiation method, study on the effect of KF content toward catalyst characteristics and biodiesel conversion was not studied yet[10]. Based on these backgrounds, aim of this research is to evaluate the effect of KF modification at varied KF content on the characteristics of catalyst and catalysis result in biodiesel conversion.

\section{Materials and Methods}

\section{Materials}

Natural kaolinite was obtained from Sukabumi, West Java, chemicals consist of KF, methanol and $\mathrm{NaOH}$ were purchased from Merck, Germany. Jatropha Oil obtained from PT Tunas Jaya was utilized for biodiesel conversion experiments.

\section{Materials Preparation}

Synthesis of KF-modified kaolinite was conducted by mixing KF salt and kaolinite powder at varied $\mathrm{KF}$ percentage of 5, 10, 25 and 30\%. The mixtures were grinded for $15 \mathrm{mins}$ followed by heating at $200^{\circ} \mathrm{C}$ for $2 \mathrm{~h}$. The obtained KF/KAOs from varied $\mathrm{KF}$ content were encoded as KF5/ $\mathrm{KAO}, \mathrm{KF} 10 / \mathrm{KAO}, \mathrm{KF} 25 / \mathrm{KAO}$ and KF30/KAO respectively. The materials were characterized by using $\mathrm{x}$-ray diffraction, gas sorption analyzer, scanning electron microscope-energy dispersive $\mathrm{x}$-ray and solid basicity.

\section{Instrumentations}

A Philips-benchtop X-ray diffractometer equipped with a Ni-filtered $\mathrm{Cu}-\mathrm{K} \alpha(1.5405 \AA)$ was used as an X-ray source to obtain the XRD patterns at running conditions for the X-ray tube $(40 \mathrm{kV}$ and $40 \mathrm{~mA}$ ). The detector scans the intensity of diffracted radiation and the peak position from $5-80^{\circ}$ and the step size of $0.4 \%$ mins.

The specific surface area and pore size distribution of materials were determined by the Brunauer-Emmet-Teller (BET) method using Quantachrome NOVA 1200 e instrument. SEMEDX of Energy dispersive X-ray fluorescence (XRF) spectrometry (JEOL) was used to capture surface morphology and determine the bulk composition of materials.

Electron microscope images were collected on scanning electron microscope (SEM, JEOL) and $\mathrm{x}$-ray diffraction analysis was performed over Philips Benchtop instrument. The surface basicity of the samples was determined by titration method. About $1 \mathrm{~g}$ of the sample was mixed with citric acid solution in an excess molar content and stirred overnight. The mixture was filtered off to get the filtrate. Amount of un-adsorbed citric acid was analyzed by using acid-base titration using ammonium hydroxide as standard. Amount of adsorbed citric acid per sample weight was calculated as solid basicity[2,3].

\section{Catalytic activity test}

The transesterification of Jatropha oil was carried out in conventional reflux and MWreflux reactor. For conventional reflux system, the experiments were performed in a $250-\mathrm{mL}$ threeneck flask reactor with rigorous electric stirring using temperature-controlled heating mantle. The mixture of jatropha oil and catalyst was added into the flask and heated to setting temperature first. Once the reaction reached certain temperature, methanol was added and the reaction conducted at certain time. For MW-assisted method, a modified commercial microwave oven was employed. The schematic representation of the MW reactor is depicted in Fig. 1. In order to determine the yield of biodiesel conversion, the mixture was filtered and collected into a flask. The upper layer which is 
containing the fatty acid methyl esters (FAME) was separated and analyzed using gas chromatographymass spectra (GCMS) analysis. Shimadzu GCMS instrument was utilized for analysis and as external standard mixture of fatty acid, FAME result obtained from reaction between Jatropha oil and methanol using $\mathrm{NaOH}$ catalyst for $6 \mathrm{~h}$.

Biodiesel conversion of Jatropha oil was conducted at direct transesterification reactions. Reactions were varied by using different methods (reflux and microwave-assisted reactions) and varied catalysts. Biodiesel products were analyzed with gas chromatograph-mass spectrometry (GCMS QP2010 Plus, Shimadzu Corporation, Japan) equipped with a flame ionization detector (FID) and a capillary column $30 \mathrm{~m} \times 0.32 \mathrm{~mm} \times 0.25 \mu \mathrm{m}$ (DB-WAX, Carbowax 20M). Yield of FAME was calculated by comparing the peak area of the biodiesel results respect to external standard of biodiesel following equation:

Yield (\%) was calculated refer to following equation:

$$
\text { Yield }(\%)=\frac{m_{1} w}{m_{2}} \times 100 \% \ldots \ldots \text { (1) }
$$

where $\mathrm{m}_{1}$ is the actual mass of biodiesel $(\mathrm{g})$, $\mathrm{m}_{2}$ is the theoretical mass of the biodiesel $(\mathrm{g})$, and $\mathrm{w}$ is the mass concentration of the biodiesel determined by GC[11]. Turnover frequency (TOF) was calculated by following equation:

$$
\text { TOF }=\frac{\text { mol }_{a c t z a l}}{t \cdot f_{b}} \times 100 \% \ldots \text { (2) }
$$

Mole actual is the moles of the biodiesel produced at time $t$ and $f_{b}$ is the total surface basicity calculated by titration method.

Composition of the fatty acid methyl ester (FAME) was analyzed with gas chromatographmass spectrometry (GC-MS QP2010 Plus, Shimadzu Corporation, Japan) equipped with a flame ionization detector (FID) and a capillary column $30 \mathrm{~m} \times 0.32 \mathrm{~mm} \times 0.25 \mu \mathrm{m}$ (DB-WAX, Carbowax 20M). Yield of FAME was calculated by where is the mass of internal standard added to the sample is the peak area of external standard is the mass of the biodiesel sample and is the peak area of the biodiesel sample.

Reusability test of catalyst materials was performed by utilization of refreshed catalyst. The refreshing process was conducted by washing reused catalyst using methanol followed by drying.

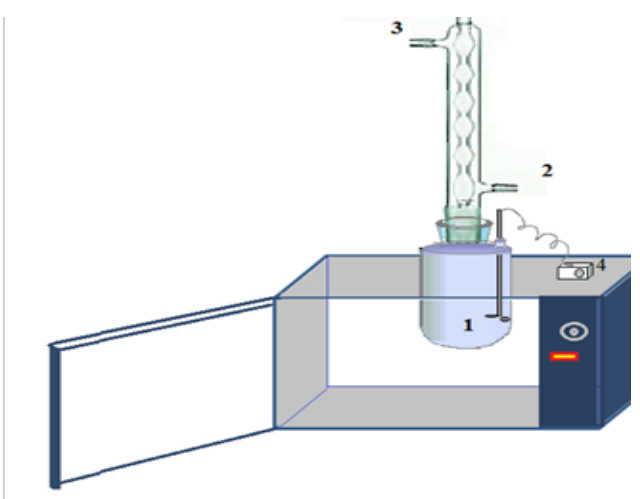

1: reaction chamber

2: water inlet

3: water outlet

4: stirrer control

Fig. 1. Scheme of MW reactor.

\section{$\underline{\text { Results and Discussion }}$}

The EDX results (Table 1) indicated that the chemical composition of the kaolinite sample typically consisted of $\mathrm{Si}, \mathrm{Al}, \mathrm{Mg}$ and $\mathrm{Na}$ with $\mathrm{Si}$ and $\mathrm{Al}$ as dominant elements. KF modification to kaolinite shows the attachment of $\mathrm{KF}$ as detected $\mathrm{K}$ content from EDX analysis. The $\mathrm{K}$ and $\mathrm{F}$ content increases as increasing $\mathrm{KF}$ percentage in the samples even in not as fix as targeted percentage of KF in the samples. Surface profile of the samples shown from SEM analysis (Fig. 2) demonstrates the platy form of kaolinite which is the characteristic of clay morphology. $\mathrm{KF}$ modification to the kaolinite produced the aggregates form in that the higher KF concentration for modification the tighter surface appeared. Similar changes from clay modification with base was reported from KF modification onto clay and $\mathrm{NaAlO}_{2}[12,13]$. Effect of KF content on surface profile is analyzed by SEM-EDX analysis. From SEM profile, it is found that the surface reflects aggregation as increasing KF content for modification.

Figure 3 shows the XRD patterns of materials. It is noted that kaolinite intense reflections are appeared at $2 \theta=12.30(\mathrm{~d}=7.18765 \AA)$ and $24.9208(\mathrm{~d}=3.57 \AA)$. Broadening reflections occurred after KF modification indicated decreasing the crystallinity of the kaolinite. As the KF loading more than $25 \%$, there are some new peaks come out. The presence of KF is identified from the reflection at around $30^{\circ}$ from $\mathrm{KF} 25 / \mathrm{KAO}$ and KF30/KAO due to high content of $\mathrm{KF}$ loaded $[14,15]$. Some new reflections are 


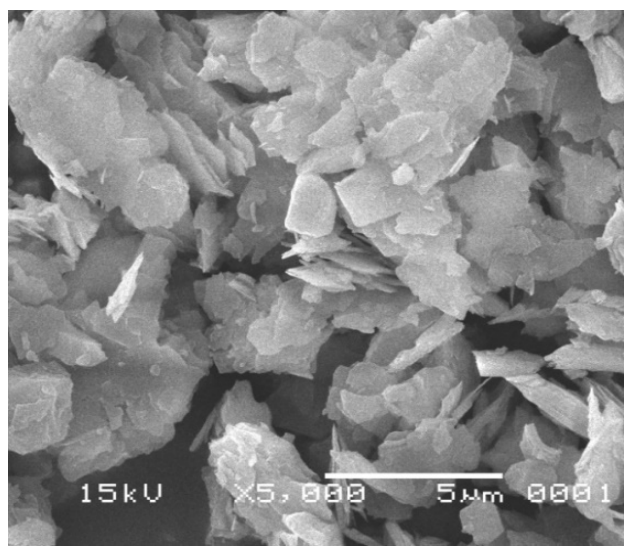

a

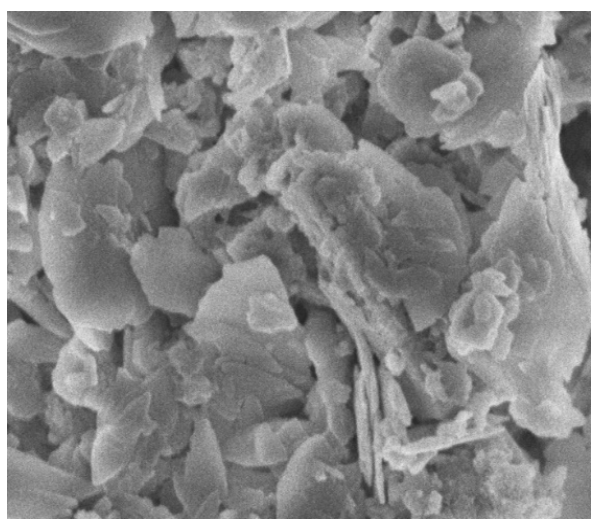

c

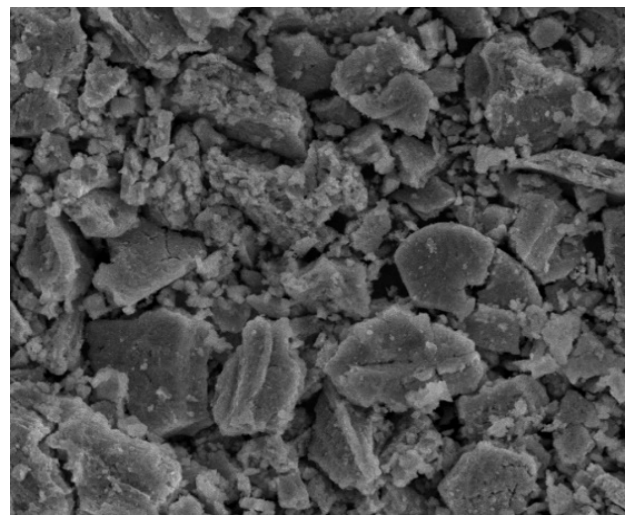

b

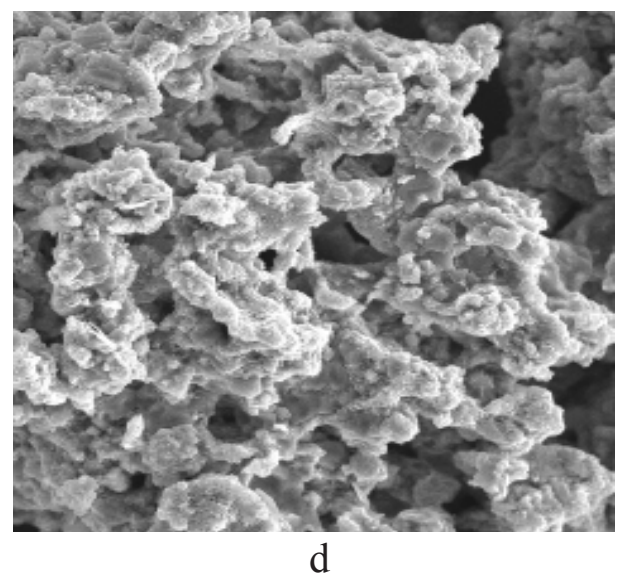

d

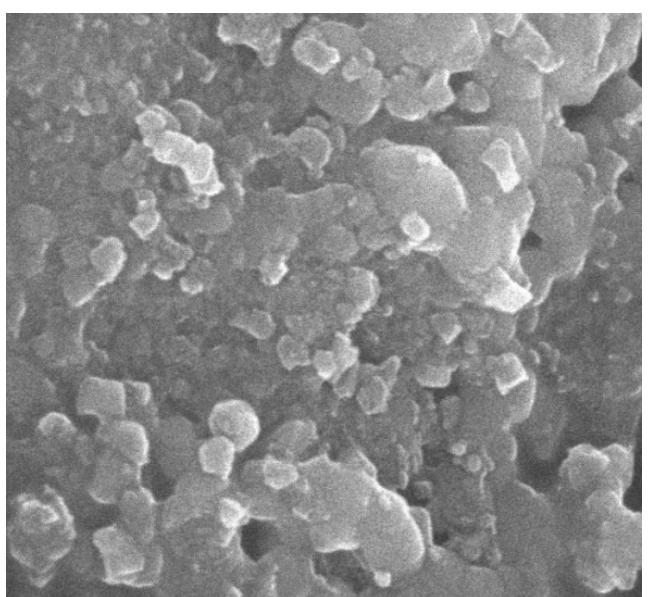

e

Fig. 2. SEM profile of (a) KAO (b) KF5/KAO (c) KF10/KAO (d) KF25/KAO (e) KF30/KAO. 
TABLE 1. Chemical composition of materials from EDX analysis.

\begin{tabular}{cccccc}
\hline Element & KAO & KF5/KAO & KF10/KAO & KF25/KAO & KF30/KAO \\
\hline $\mathrm{Si}$ & 36.59 & 34.55 & 34.12 & 31.34 & 18.45 \\
$\mathrm{Al}$ & 10.51 & 11.23 & 11.12 & 10.12 & 9.08 \\
$\mathrm{Ca}$ & 0.04 & 0.03 & 0.01 & 0.01 & 0.02 \\
$\mathrm{Mg}$ & 0.06 & 0.03 & 0.01 & 0.01 & 0.01 \\
$\mathrm{~K}$ & nd & 3.21 & 8.56 & 21.33 & 29.80 \\
$\mathrm{~F}$ & nd & 3.83 & 7.90 & 19.89 & 24.25 \\
$\mathrm{Na}$ & 0.1 & n.d & n.d & n.d & n.d \\
\hline
\end{tabular}

*n.d $=$ not detected

identified as the possible phase formed such as $\mathrm{K}_{3} \mathrm{AlF}_{6}$ formation along the decreasing reflection as indication of kaolinite phase. Those reflections are the peaks at $29.7^{\circ}, 36^{\circ}$ and $42^{\circ}$ which are correspond to (220), (222) and (400) refer to JCPDS file 30-1144[12]. The combination of KF reflection and $\mathrm{K}_{3} \mathrm{AlF}_{6}$ reflections revealed the dealumination and demineralization of kaolinite structure caused by fluorination process as interaction of high content of $\mathrm{KF}$ with $\mathrm{Al}$ from $\mathrm{Al}_{2} \mathrm{O}_{3}$ impurities or $\mathrm{Al}$ from clay structure $[16,17]$. Similar dealumination and fluorination formed $\mathrm{K}_{2} \mathrm{FeF}_{4}$ caused by $\mathrm{KF}$ modification were reported from the modification of montmorillonite[9,18]. The dealumination process means that aluminium content still stays in the hole material but it is present in other phases rather than kaolinite structure as revealed from the formation of ew $\mathrm{K} 3 \mathrm{AlF} 6$ phase in XRD analysis.

The evolution of surface morphology and change in XRD pattern are well-corelated with the surface profile of samples identified from gas sorption analysis. Adsorption-desorption isotherm and pore distribution of materials are presented in Fig. 4 and calculated surface parameters are listed in Table 2. The patterns show the increasing ability of the materials to adsorb $\mathrm{N}_{2}$ after KF modification. It can be observed that as the higher $\mathrm{KF}$ concentration used in the modification the dominant porous size and specific surface area become higher until the KF content of $10 \%$ (KF5/ $\mathrm{KAO}$ and $\mathrm{KF} 10 / \mathrm{KAO})$. It is related to the change in adsorption-desorption profile which demonstrates the hysteresis loop of adsorption and desorption pattern as higher KF concentration utilized. In advance, further increasing KF content (KF25/ $\mathrm{KAO}$ and $\mathrm{KF} 30 / \mathrm{KAO}$ ) gives tendency to reduce specific surface area and pore volume but they are still higher compared to those parameters of raw kaolinite sample. Due to pore radius data of both, the decreasing surface area and pore radius may be related to the formation of aggregates between kaolinite layers such as the formation of house of card structure. The KF modification is strongly affected to the increasing surface basicity but it depicts a relative constant value in between KF25/ $\mathrm{KAO}$ and KF30/KAO samples. This phenomenon is in line with some previous works was reported for KF modification onto clay materials. The a volcano-type behavior of KF effect to the surface basicity was reported in clay modification at the KF content of 5-40\%[18].

The catalytic performance of kaolinite and KF-modified kaolinite samples are shown by the kinetics of biodiesel conversion of Jatropha oil over conventional reflux and microwave-assisted methods. As shown in Fig. 4, effect of the KF modification shows noticeable improvement of the catalytic performance. In all varied time of reactions, KF-modified samples demonstrate express the higher yield compared to raw kaolinite. Since KAO express a relative stable yield over varied time of reaction, noticeable yield enhancement of the conversion by KF-modified samples is observed. The kinetics pattern suggests that KF-modified kaolinite catalysts are more active in the reaction by contributing basic sites for the mechanism, while other parameters such as surface area, pore volume and pore radius is not directly related with the increasing conversion.

From comparison on the use of conventional reflux and $\mathrm{MW}$-assisted methods, it is noted that 30 mins $\mathrm{MW}$-assisted reaction and reflux 
for 3 hours give similar yield values indicating the time-effective process of $\mathrm{MW}$ - assisted method. It can be confirmed from the higher turnover frequency (TON) of the process over all catalyst. As many reports of MW-assisted transesterification reaction, the higher TON is related to the more effective collision of the reactants through activation of the interacting molecules and catalyst in the system effective and efficiently[19-21].

The effectivity of KF-modified kaolinite is also related to the reusability of the catalyst over MW-assisted method depicted in Fig. 6.

Upon the KF modification, the higher $\mathrm{KF}$ loading gives better reusability since the KF- modified samples give relatively high yield percentage compared to the yield from first usage. It is also found that the use of MW for biodiesel conversion was greatly influenced to enhance reusability. The pattern of surface basicity change and yield along reusability are indicative for the releasing basicity and the reduction of active sites from longer time of catalyst usage. The longer utilization of the catalyst reduces surface basicity produces faster basicity release and it linearly affects the conversion yield. Over the comparison on the relationship between solid basicity and yield, it is found that linear correlation appears from the utilization of reflux method while from MW-assisted conversion, their correlation is in polynomial pattern (Fig. 7). This difference
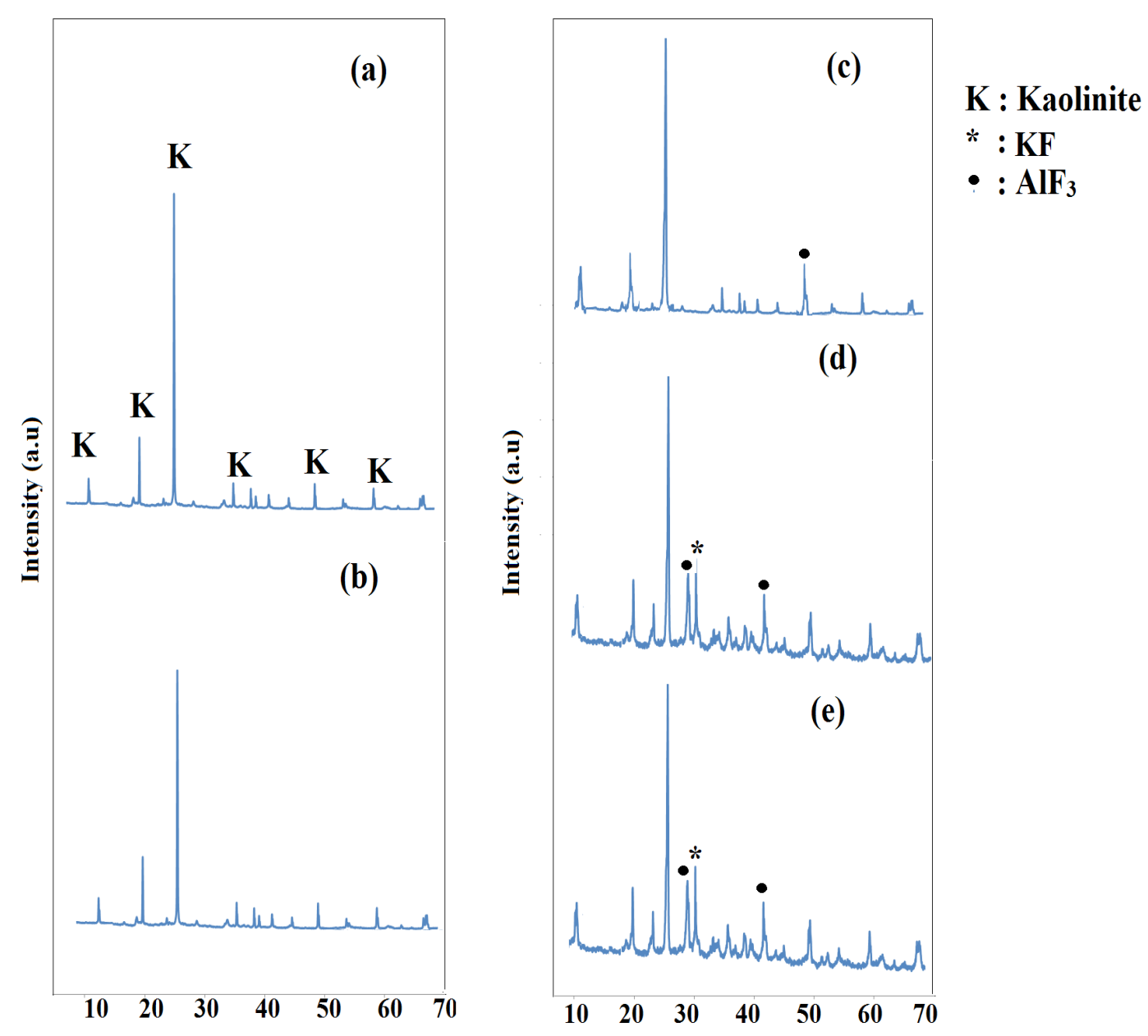

Fig. 3. XRD profile of (a) KAO (b) KF5/KAO (c) KF10/KAO (d) KF25/KAO (e) KF30/KAO. 


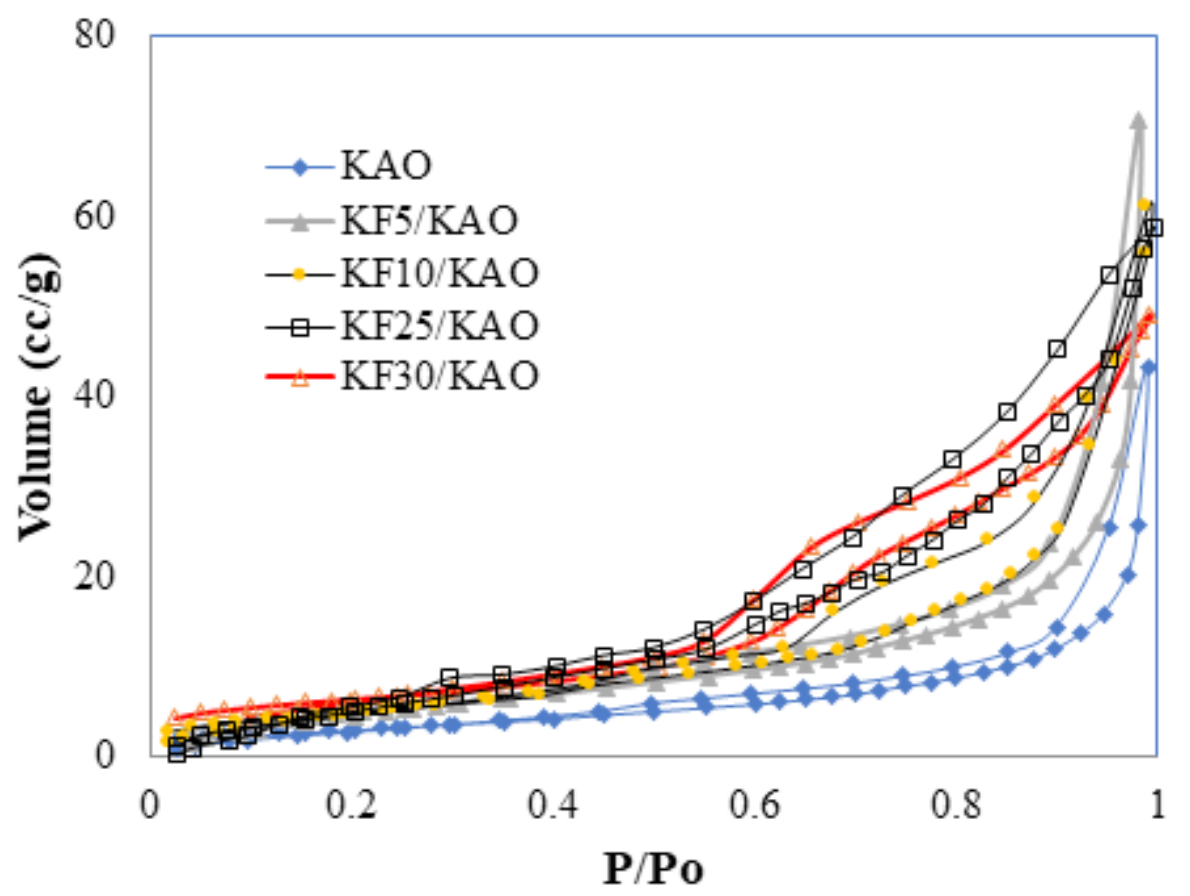

(a)

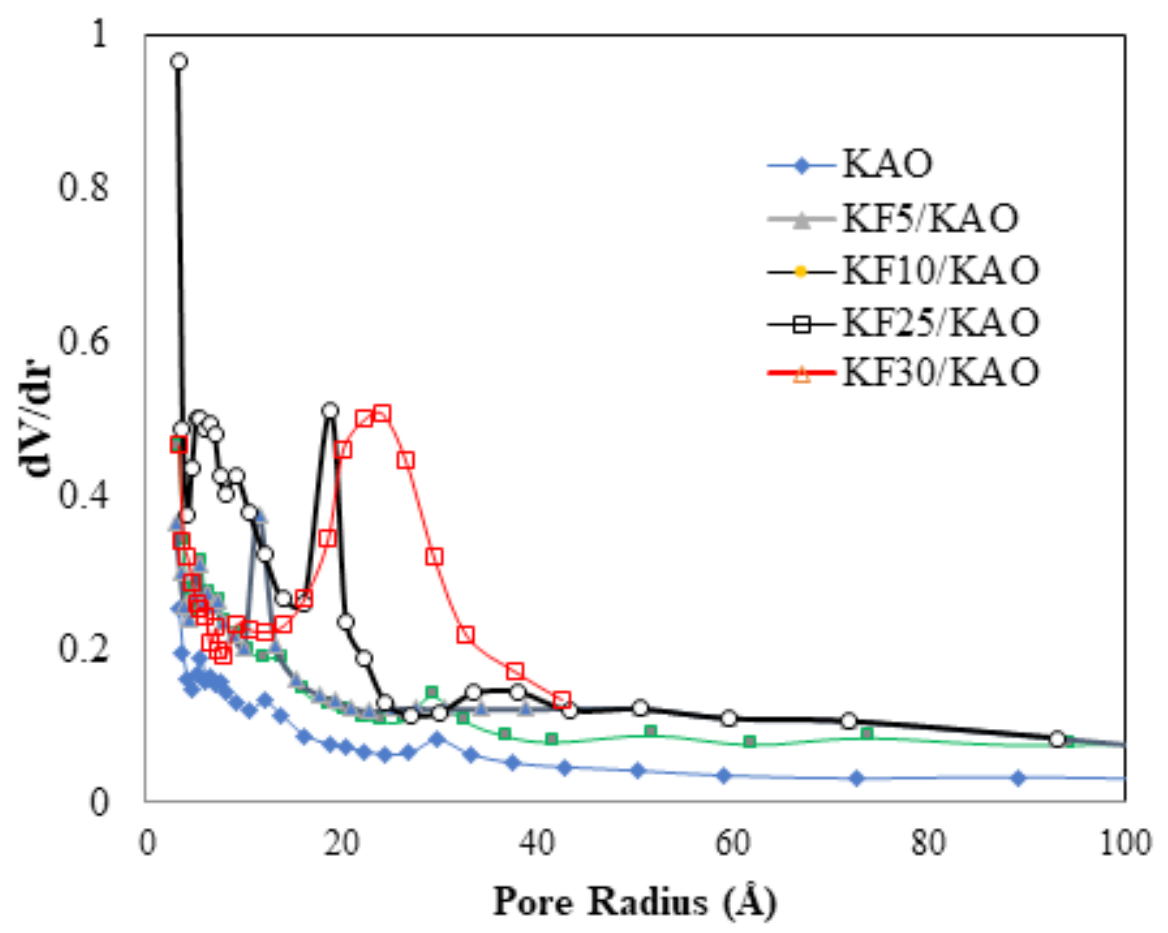

(b)

Fig. 4. (a) Adsorption-desorption profile of materials (b) Pore distribution of materials. 
TABLE 2. Surface parameters calculated from gas sorption analysis and the solid basicity of materials.

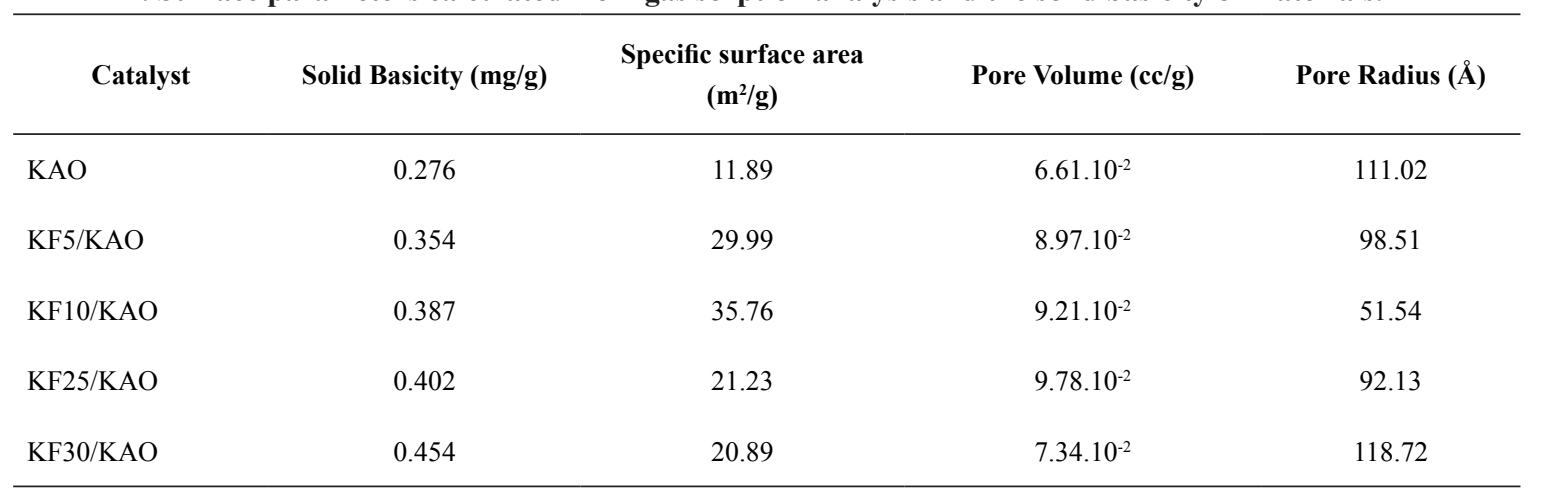
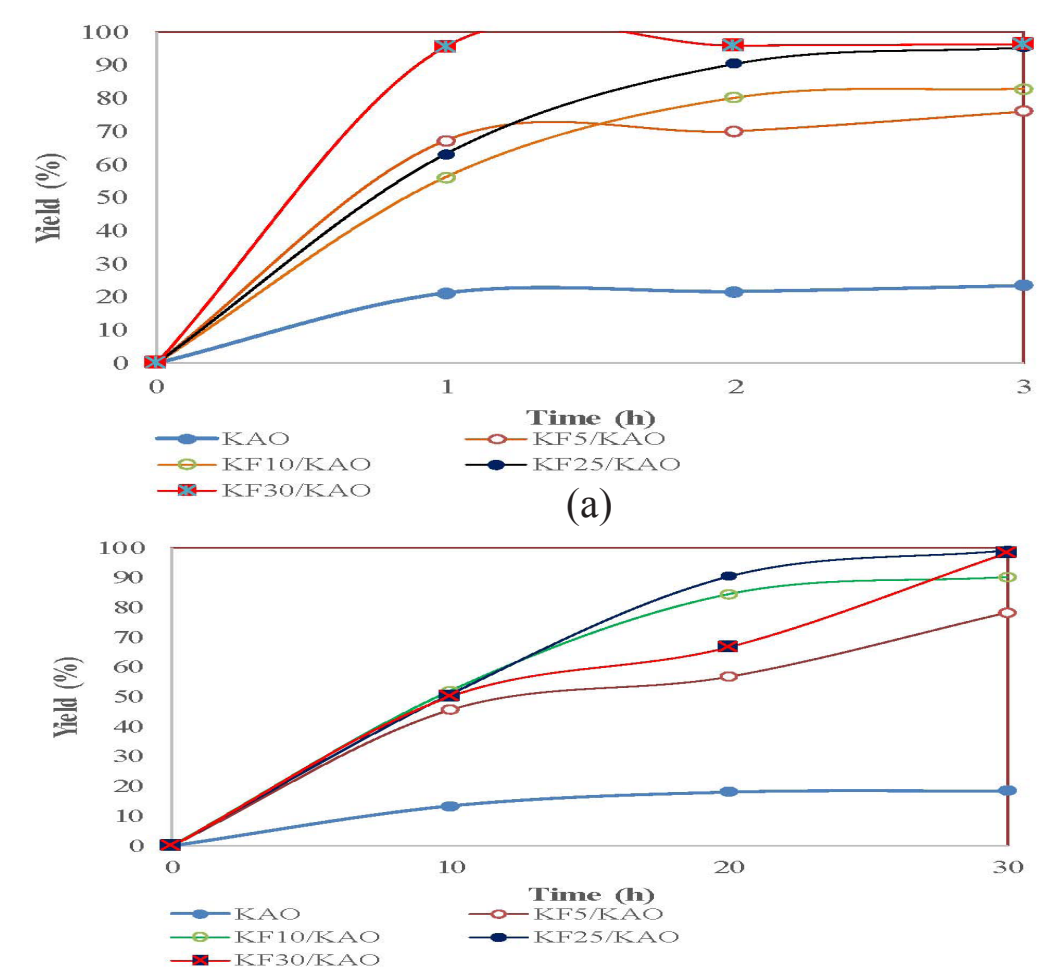

(b)

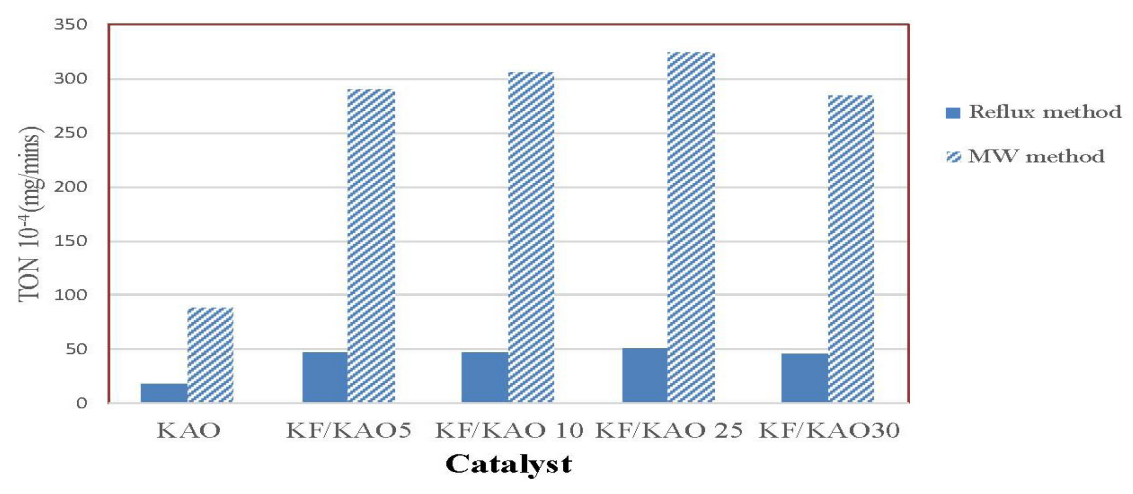

(c)

Fig 5. (a) Kinetics of biodiesel conversion over varied catalysts by using reflux method (b) Kinetics of biodiesel conversion over varied catalysts by using MW method (c) Comparison on TON of reflux and MW method j

Egypt. J. Chem. 61, No. 1 (2018) 

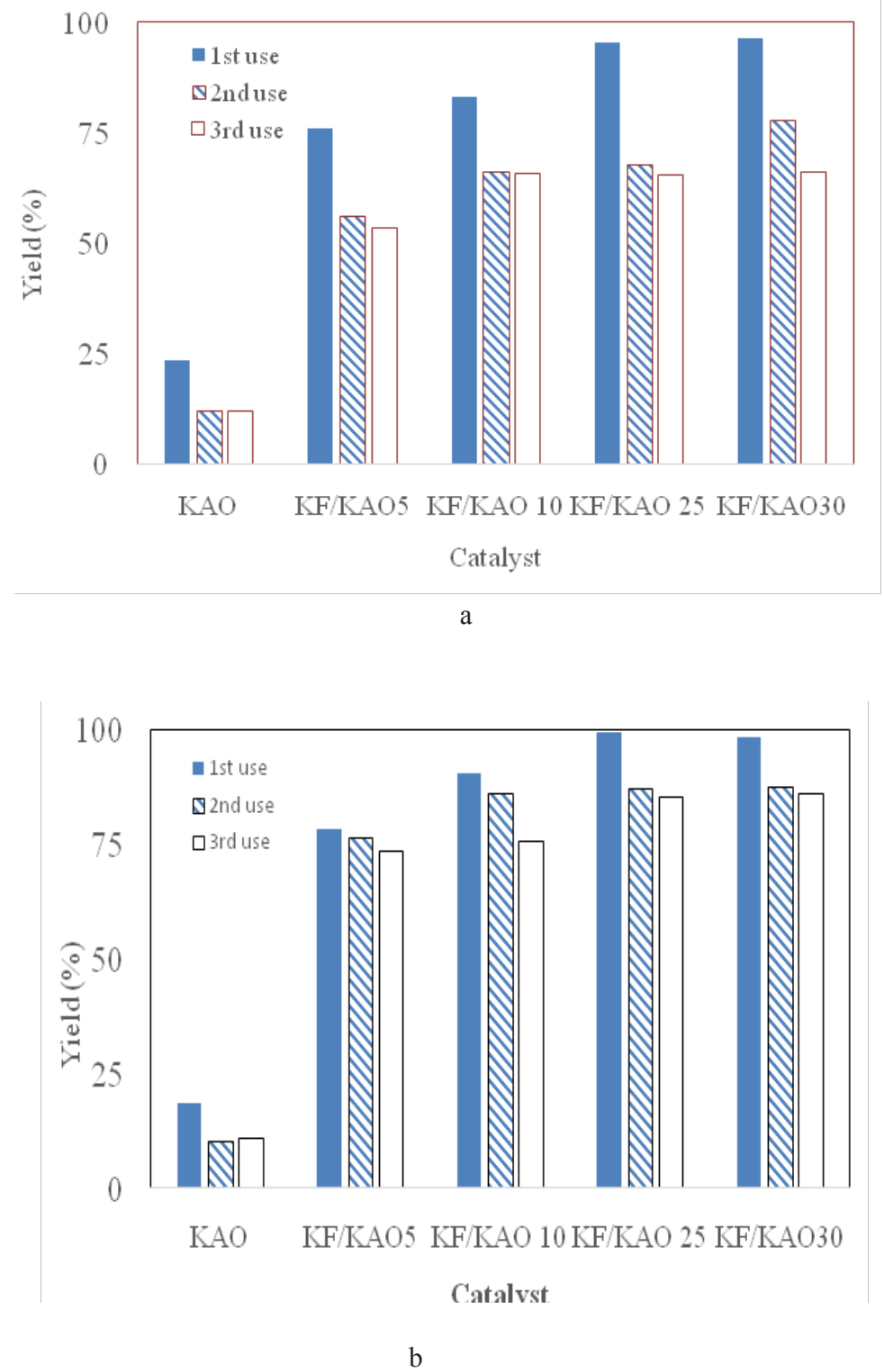

Fig. 6. Comparison of biodiesel yield over varied fresh and reused catalysts by (a) reflux method (b) MW-assisted method.

suggests that basicity is not only the main factor for increasing the yield over MW-assisted reaction system but the contribution of irradiation that accelerate the intensive collision between reactants and catalyst is also another important factor[22,23].

\section{Conclusion}

In summary, KF-modification to kaolinite exhibit the increasing physicochemical character especially those are related to the catalytic performance in biodiesel conversion. The KF loaded is significantly contribute to increasing solid basicity which is found to be the responsible character for enhancing the yield of conversion. Furthermore, the use of MW in biodiesel conversion gives similar results in shorter time and better reusability. 


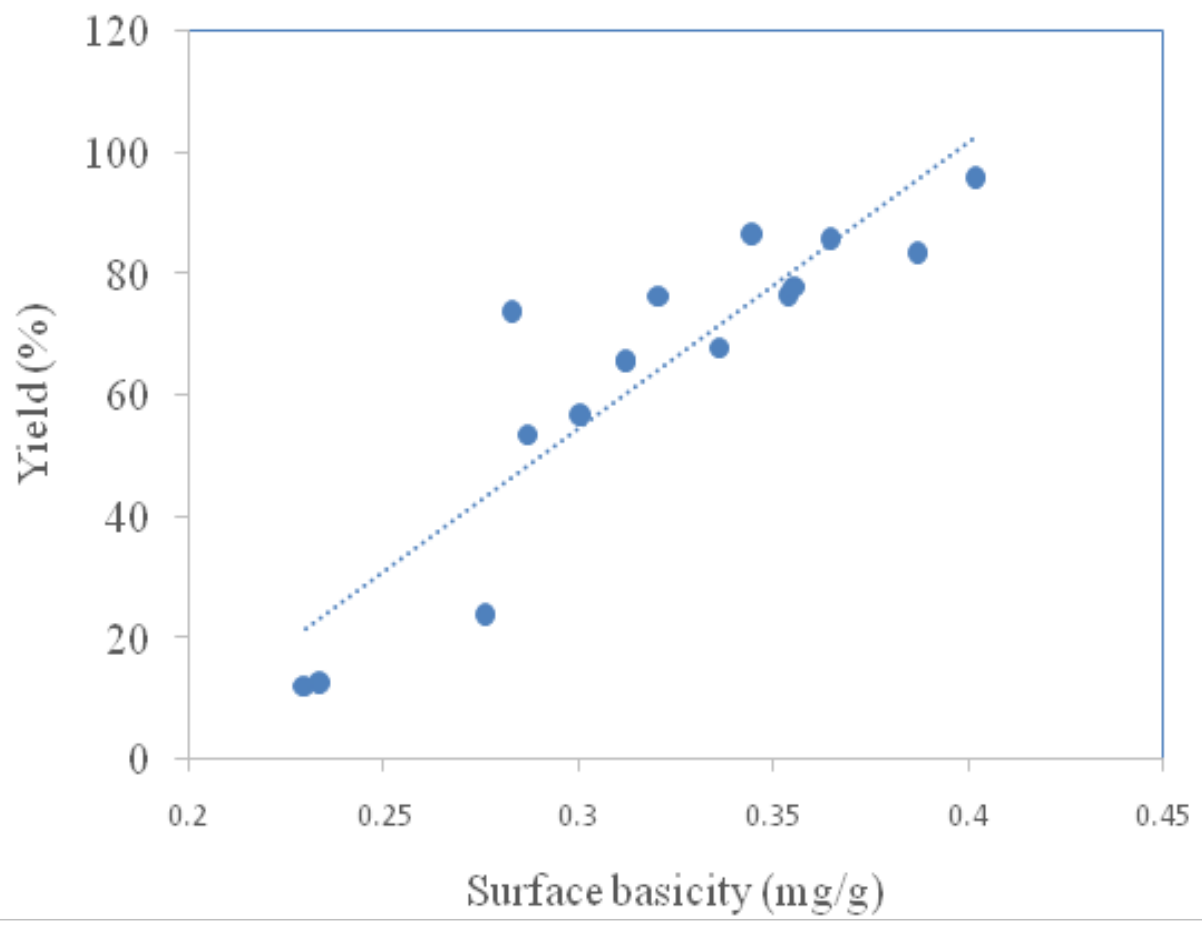

(a)

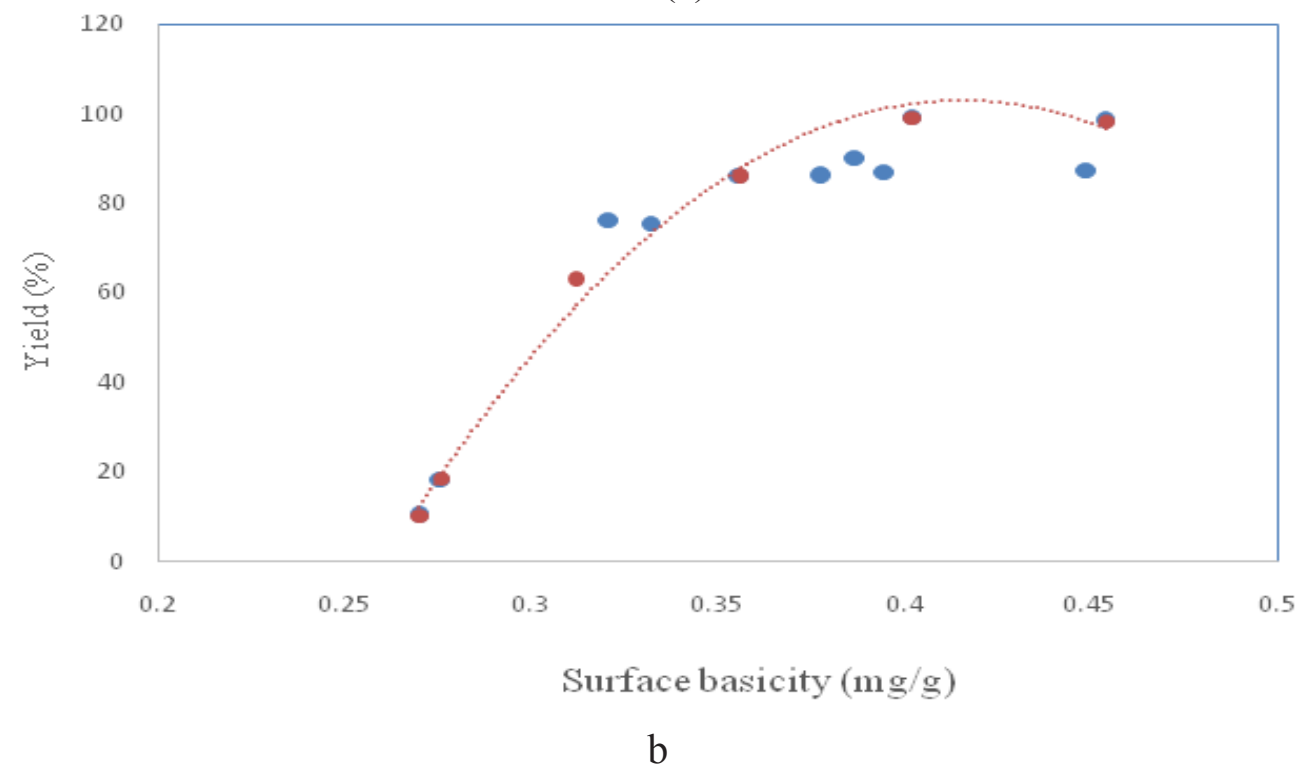

Fig. 7. Relationship between solid basicity and yield of biodiesel conversion using (a) reflux method (b) MWassisted method

\section{$\underline{\text { References }}$}

1. Guo, F. and Fang, Z., Biodiesel Feedstocks and Processing Technologies, 1 (2011).

2. Atadashi, I. M., Aroua, M. K., Abdul Aziz, A. R. \& Sulaiman, N. M. N., Journal of Industrial and Engineering Chemistry 19, p.14. (2013).
3. Ramirez-Ortiz, J., Martinez, M. and Flores, H., Frontiers of Chemical Science and Engineering, 6, p.439 (2012).

4. Nascimento, A. R. Do et al. Materials Research 18, p.283 (2015).

5. Degirmenbasi, N., Boz, N. and Kalyon, D. M.

Egypt. J. Chem. 61, No. 1 (2018) 
Applied Catalysis B: Environmental, 150-151, p.147 (2014).

6. Farias, A. F. F. et al.. Fuel 160, p.357 (2015).

7. Abdullah, A. Z., Wibowo, T. Y. and Zakaria, R. E. Chemical Engineering Journal, 167, p.328 (2011).

8. El Sherbiny, S. A., Refaat, A. A. and El Sheltawy, S. T. Journal of Advanced Research,1, p.309 (2010).

9. Alves, H. J. et al. Applied Clay Science. 91-92, p.98 (2014).

10. Fatimah, I., Andiena, R. Z. and Yudha, S. P. Journal of Physics: Conference Series, 755, p.11001 (2016).

11. Chen, J., Jia, L., Guo, X., Xiang, L. and Lou, S. RSC Adv. 4, p.60025 (2014).

12. Abakumov, A. A. et al. Journal of Solid State Chemistry 179, p.421 (2006).

13. Silva, L. C. A. et al. Applied Clay Science, 102, p.121 (2014).

14. Murugan, C. and Bajaj, H. C. Indian Journal of Chemistry - Section A Inorganic, Physical, Theoretical and Analytical Chemistry, 49, p.1182 (2010).
15. Tang, Y., Ren, H., Chang, F., Gu, X. and Zhang, J., RSC Adv. 7, p.5694 (2017).

16. Husssein, S. M., Shihab, O. H., Ibrahim, S. S. and Ahmed, N. M.,. World Journal of Nano Science and Engineering 5, p.1 (2015).

17. Zaitseva, Y. N., Yakimov, I. S. and Kirik, S. D. Open Journal of Metal, 2013, p.86-91 (2013).

18. Jia, L. et al. Research on Chemical Intermediates, 42, p.1791 (2016).

19. Lieu, T., Yusup, S. and Moniruzzaman, M. Bioresource Technology, 211, p.248 (2016).

20. Singh, V. \& Sharma, Y. C. Energy Conversion and Management 138, p.627 (2017).

21. Cheng, J. et al. Bioresource Technology, 221, p.344 (2016).

22. Venkatesh Kamath, H., Regupathi, I. and Saidutta, M. B. Fuel Processing Technology, 92, p.100 (2011).

23. Lindstorm, P. Tierney, J. and Westman, J., Tetrahedron. 57, (2001).

(Received 11/ 11/2017; accepted 7 / 2 / 2018) 